\title{
Environmental Impact Assessment of Post Tensioned and Reinforced Concrete Slab Construction
}

\author{
D. Miller, J.H. Doh, H.Guan, and M. Mulvey \\ Griffith School of Engineering, Griffith University, Gold Coast, Australia
}

S. Fragomeni

School of Engineering and Science, Victoria University, Melbourne, Australia

T. McCarthy

Department of Civil, Mining and Environmental Engineering, University of Wollongong, Australia

T. Peters

ADG Consulting Engineers

ABSTRACT: In Australia, approximately 30 million tonnes of finished building products are produced each year, with over $56 \%$ of this quantity, by mass, being attributed to concrete and a further $6 \%$, steel, highlighting the importance of maximising design efficiencies. The cement industry has been reported responsible for $5 \%$ of global carbon dioxide emissions while the construction, operation and maintenance of buildings are estimated to account for 50\% of all energy usage and more than $50 \%$ of all anthropogenic greenhouse gas (GHG) emissions globally. This research determines some environmental advantages achievable through application of alternate concrete slab construction methods for a typical 10-storey office structure. Structural analysis results indicate a $36.9 \%$ reduction in concrete volume and $43.4 \%$ reduction in steel mass in a post tensioned slab structure in comparison with a conventional reinforced slab system. Similar results were observed when comparing reductions in embodied energy and global warming potential. These results highlight the improvements possible by the incorporation of improved sustainable design methods.

\section{INTRODUCTION}

The building and construction sector is a major contributor to environmental degradation in Australia, accounting for the largest share in natural resource depletion and energy usage. Studies carried out by the Organization for Economic Cooperation and Development (OECD) have revealed that the construction, operation and maintenance of residential and commercial buildings account for 30\% of all energy usage and more than $30 \%$ of all anthropogenic greenhouse gas emissions in OECD countries (Yeo \& Gabbai 2011). For Australia in particular, residential and commercial buildings account for $23 \%$, or 130 megatonnes, of Australia's total greenhouse gas emissions (World Green Building Council 2009).

With Australia's population predicted to increase to approximately 35.5 million by 2056, the energy usage and greenhouse gas emissions generated by the building and construction sector are expected to skyrocket (Australian Bureau of Statistics 2010). This growth has already led to the built environment being identified as the largest single anthropogenic contributor to climate change. As a result, actions must be taken to minimise resource usage and curb greenhouse gas emissions produced by this sector. The primary focus of this study was concrete slab construction, particularly the efficiency in their use by the construction industry. In 2005, it was revealed that steel and concrete accounted for approx- imately $41 \%$ of the global warming impacts caused by the building sector in Australia (Walker-Morison et al. 2007). Therefore, any reduction in the usage of these materials through environmentally sustainable design practices will lead to massive reductions in Australia's GHG emissions.

Environmentally Sustainable Design (ESD) endeavors to use design principles and strategies to reduce the environmental impacts caused by the construction and operation of buildings (Palich et al. 2011). In the current building design process, structural engineers play a limited role in the overall sustainability of a design, with the architect and client being mostly responsible for such decisions (Kestner 2007). However, structural engineers have the ability and responsibility to incorporate ESD into current design methodologies by aiming to improve the structural effectiveness of a building. This is achieved through the improved efficiency of a structural system while maintaining equivalent structural performance. Providing tools to be able to achieve this was one of the major intentions of this study.

The amalgamation of sustainable design philosophy and quantification techniques into the design of concrete structures is an emerging area of research in the engineering community. Particularly, few investigations have been undertaken to try and improve the sustainability of individual structural elements (Kelly \& McCarthy 2008). In response to this, 
the project was undertaken to investigate ways to help implement sustainable design into mainstream structural design practices.

The aim of this research is to utilise sustainable design methodologies to compare corresponding environmental impacts of equivalent office mid-rise structures in the South East Queensland region, when post tensioning and conventional reinforcing construction methods are implemented. The results of this study will facilitate improvement of the environmental efficiency of office buildings, helping instigate the need for national design codes and rating systems, targeting embodied energy. Using an appropriate quantification technique and a relative measure, including embodied energy and global warming potential, a comparison between different designs can be made which enables the selection of the optimum design solution for a slab system in a typical office structure.

\section{METHODOLOGY}

To achieve this, a multi-stage research methodology was formulated. This methodology, as shown in Figure 1, indicates that the research can be categorised into two major components, Structural Design and Environmental Analysis.

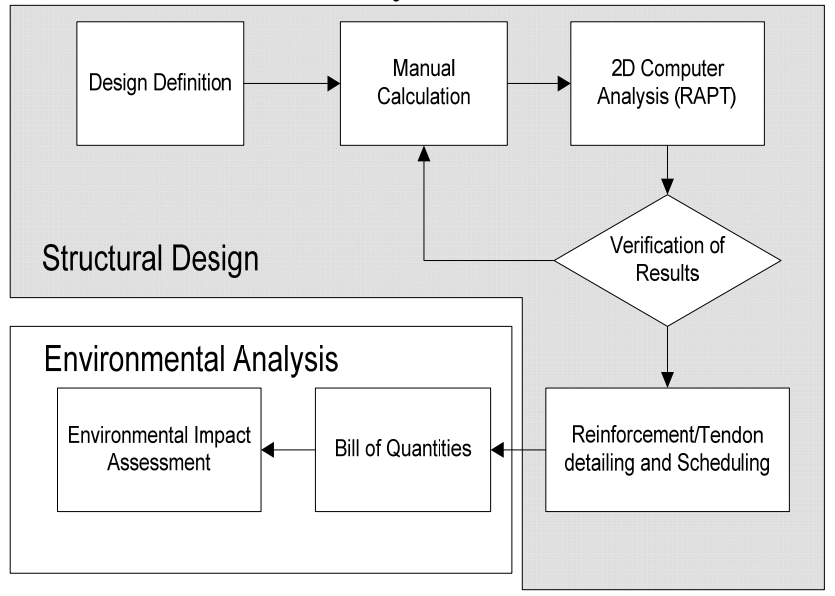

Figure 1 Methodology for Structural Design and Environmental analysis

The Structural Design consisted of several distinct components: 1) Design Definition stage involved formulating the design of the specific building to be analysed and identified with any assumptions that were necessary to undertake the analysis; 2) Manual Calculations were then undertaken to provide a detailed design of the structural element (slab), that was used for inputs into the two dimensional computer analysis program, RAPT; 3) The structural 2D designs were finalised using the results obtained from the computer analysis that were verified with the manual calculations to ensure accuracy, economics and suitability of the design; 4) The reinforcement requirements for each structural element were subsequently detailed in accordance with Australian Standards (AS3600-09) and guidelines that allowed a detailed bill of quantities to be formulated. Using the bill of quantities, an Environmental Impact Assessment (EIA) was undertaken using data obtained from the extensive literature review (Treloar et al. 2001, Lawson 2000, Norgate \& Rankin 2002, Aye et al. 2011, Crawford 2011), to calculate an indicative value for the environmental impact of each structure in terms of embodied energy and carbon dioxide equivalent emissions (Global Warming Potential, GWP) as shown in Table 1. While it is noted that high strength steel tendon fibres undergo different manufacturing procedures, there is significant limitations in identifying suitably accurate values. There was no values specified for embodied energy of steel tendons in the study undertaken by Crawford (2011).

Table 1. Embodied Energy and $\mathrm{CO}_{2}$ Equivalent values to be utilised in the Environmental Impact Assessment

\begin{tabular}{|l|l|l|}
\hline $\begin{array}{l}\text { Construction Mate- } \\
\text { rial }\end{array}$ & Embodied Energy & $\begin{array}{l}\text { GWP (100 year } \\
\mathrm{CO}_{2} \text {-e) }\end{array}$ \\
\hline Concrete $(32 \mathrm{MPa})$ & $4880.4 \mathrm{MJ} / \mathrm{m}^{3}$ & $292.824 \mathrm{~kg} / \mathrm{m}^{3}$ \\
\hline Concrete $(40 \mathrm{MPa})$ & $5670 \mathrm{MJ} / \mathrm{m}^{3}$ & $340.2 \mathrm{~kg} / \mathrm{m}^{3}$ \\
\hline Concrete $(50 \mathrm{MPa})$ & $7182 \mathrm{MJ} / \mathrm{m}^{3}$ & $430.92 \mathrm{~kg} / \mathrm{m}^{3}$ \\
\hline Concrete $(65 \mathrm{MPa})$ & $10348.8 \mathrm{MJ} / \mathrm{m}^{3}$ & $620.928 \mathrm{~kg} / \mathrm{m}^{3}$ \\
\hline $\begin{array}{l}\text { Steel Reinforce- } \\
\text { ment }\end{array}$ & $85.46 \mathrm{GJ} /$ tonne & $5127.6 \mathrm{~kg} /$ tonne \\
\hline Galvanised Steel & $38 \mathrm{GJ} /$ tonne & $2280 \mathrm{~kg} /$ tonne \\
\hline
\end{tabular}

\subsection{Design Post tensioned and Reinforced Concrete slab}

The typical office structure investigated comprised of a 10 story building. This was designed and analysed using both post tensioned and conventional reinforced concrete slabs with the concrete strength of $32 \mathrm{MPa}$. The slab span was varied to evaluate four column centre spacings of 6.67, 8, 10 and 13.33 metres. This layout resulted in the analysis of the building containing 3-6 clear spans for the total exterior building footprint of $40.5 \times 40.5$ metres. Typical flat plate slab construction system was used, which was supported on a square grid of $500 \times 500 \mathrm{~mm}^{2}$ columns with $3.5 \mathrm{~m}$ floor to floor heights.

To meet all relevant standards including structural adequacy, durability, fire resistance and acoustic performance, a minimum slab depth of $200 \mathrm{~mm}$ was required along with a minimum clear cover of $29 \mathrm{~mm}$ to provide a minimum axis depth of $35 \mathrm{~mm}$ when N12 bars are utilised. For the post tensioned slabs, the code specifies an additional $10 \mathrm{~mm}$ concrete cover to tendons than that required for typical reinforcement. This requirement was accounted for by allowing 30mm clear cover to the duct. The additional cover is available within the void, therefore this design meets all relevant requirements. 


\subsection{Design for Serviceability}

Design for compliance with the serviceability limit state includes requirements for both deflection and crack control. Deflection control in the conventional reinforced slab was achieved through compliance with the deemed-to-comply span on depth ratio, which was applied in determination of the required slab thickness.

Determination of the required slab thickness is an iterative process, which continues through the analysis and is affected by many factors. The most efficient slab will display a minimum required thickness to control deflection and punching shear whilst maintaining acceptable reinforcement requirements.

Typical floor and roof slabs for an office were designed to provide comparable structural performance indicated by long-term deflection estimates, which were limited to a maximum of:

$$
\frac{\Delta}{\text { Lef }} \leq \frac{1}{250}
$$

In addition to this, a minimum control over incremental deflection for all floor slabs should be satisfied by

$$
\frac{\Delta}{\text { Lef }} \leq \frac{1}{500}
$$

Application of these minimum deflection limits using the deemed to comply span-to-depth ratio for reinforced concrete slabs, as detailed in Clause 9.3.4, provides an initial indication of the required thickness for the reinforced concrete slabs.

The code, on the other hand, provides no methods to determine the thickness of a post tensioned slab. In large spans, it is more effective to use a spandepth ratio to determine the slab thickness. While various span-depth ratios are suggested in a number of published literature, the most economical slab span to depth ratio (L/D) for a post tensioned flat plate is between 37 and 40 (CCAA, 2003). Therefore, a $\mathrm{L} / \mathrm{D}$ ratio of 38 was adopted to determine the preliminary thickness of the post-tensioned slabs analysed. In large spans however, this deflection has been limited to below $50 \mathrm{~mm}$, which is appropriate for practical office applications and finishes (CCAA, 2003).

\subsection{Computer Analysis and Verification}

The RAPT implements two dimensional frame methods to analyse design strips of a slab. Improved accuracy in RAPT provides more efficient results than manual calculations, however advantages are limited by the two dimensional approach. Selection to design in accordance with AS3600-2009 ensures compliance with the standards through the application of relevant formulas and design checks.
To satisfy both Eqs. (1) and (2), the deflection to span ratios were observed and presented in Table 2. As indicated in the incremental and long-term deflection, those minimum deflection limits will result in impractical deflections for some span lengths. These deflection to span ratio should be minimised as much as possible, as large deflections can be visually unacceptable.

Table 2. Deflection to Span ratios

\begin{tabular}{|c|c|c|c|c|c|c|}
\hline & \multicolumn{3}{|c|}{$\begin{array}{c}\text { Conventional Reinforced } \\
\text { concrete }\end{array}$} & \multicolumn{3}{c|}{ Post Tensioned } \\
\hline $\begin{array}{l}\text { Span } \\
(\mathrm{m})\end{array}$ & $\begin{array}{l}\text { Incre- } \\
\text { mental } \\
\text { (floor) }\end{array}$ & $\begin{array}{l}\text { Long } \\
\text { term } \\
\text { (floor) }\end{array}$ & $\begin{array}{l}\text { Long } \\
\text { term } \\
\text { (Roof) }\end{array}$ & $\begin{array}{l}\text { Incre- } \\
\text { mental } \\
\text { (floor) }\end{array}$ & $\begin{array}{l}\text { Long } \\
\text { Term } \\
\text { (floor) }\end{array}$ & $\begin{array}{l}\text { Long } \\
\text { Term } \\
\text { (Roof) }\end{array}$ \\
\hline 6.67 & 502 & 424 & 254 & 510 & 478 & 395 \\
\hline 8 & 500 & 410 & 254 & 518 & 547 & 252 \\
\hline 10 & 512 & 414 & 250 & 500 & 479 & 250 \\
\hline 13.33 & 515 & 404 & 261 & 504 & 458 & 253 \\
\hline
\end{tabular}

Table 3. Slab thickness

\begin{tabular}{|c|c|c|c|c|}
\hline & \multicolumn{2}{|c|}{$\begin{array}{c}\text { Conventional Reinforced } \\
\text { concrete }\end{array}$} & \multicolumn{2}{c|}{ Post Tensioned } \\
\hline Span (m) & Floor (mm) & Roof (mm) & Floor (mm) & Roof (mm) \\
\hline 6.67 & 335 & 235 & 250 & 200 \\
\hline 8 & 415 & 300 & 270 & 210 \\
\hline 10 & 555 & 400 & 360 & 290 \\
\hline 13.33 & 830 & 635 & 520 & 400 \\
\hline
\end{tabular}

As long as both the manual and RAPT deflections are less than the allowable limits, the design is adequate in terms of deflection control requirements.

Another serviceability requirement in the design of structural concrete elements is crack control. Crack control requirements for flexure vary in reinforced and post tensioned applications as stipulated in Clause 9.4.

After satisfying all limit state and serviceability requirements, the minimum required depths for all slabs can be determined by an iterative process resulting in the depths presented in Table 3.

\subsection{Reinforcements detailing}

Sufficient reinforcement must be provided in a slab to satisfy strength and serviceability requirements. Reinforcement requirements were initially completed to satisfy flexural strength requirements while remaining limit state conditions and detailing considerations were subsequently checked to ensure compliance with AS3600. As such, the punching shear reinforcement requirements as stipulated in Clause 9.2; additional reinforcement requirements for crack control; and the minimum lengths of the additional reinforcement governed by Clause 9.1.3.4 should be verified.

Two dimensional RAPT modelling determined the detailing of tendon profiles and the maximum spacing between tendons in post tensioned slabs. These details are not discussed in AS3600-2009. 
After optimising and verifying the slab design by examining both RAPT and manual calculation results, construction drawings were produced detailing reinforcement and tendon requirements. This enabled the generation of a bill of quantities through which the appropriate environmental performance comparisons could be conducted.

\section{RESULTS AND DISCUSSION}

Material requirements as determined from the bill of quantities were applied factors to quantify the environmental impacts of materials in each floor and roof slab. Slab results were combined together with concrete columns to form results for whole building material requirements.

These material requirements, as determined from the bill of quantities for alternate slab construction techniques are presented below in Figures 2 and 3, respectively. Results indicate a significant reduction in material requirements being achieved through the implementation of post-tensioned construction methods.

Using a typical concrete strength of $32 \mathrm{MPa}$, it was found that the reductions in concrete volume, through the use of post tensioning, increases with increasing span length, ranging from approximately $22.9 \%$ for a $6.67 \mathrm{~m}$ span and increasing up to $37.0 \%$ for a $13.33 \mathrm{~m}$ span. This indicates that the use of post tensioning in large spans is more efficient in terms of material reductions

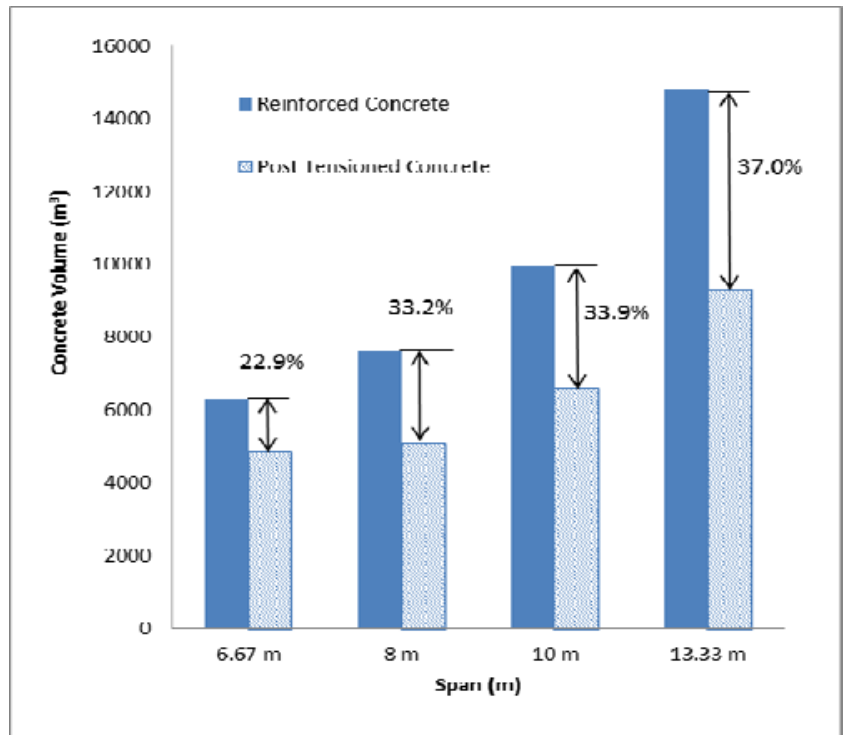

Figure 2 Concrete volumes of Reinforced and Post Tensioned Concrete buildings

Similar reductions in steel material requirements are evident with increased span as shown in Figure 3 . It is however, evident that the $6.67 \mathrm{~m}$ span achieves the largest material reduction when the post-tensioned construction technique is used. Gen- erally, it shows that the span length plays a large role in this, being able to reduce the steel mass by between $21 \%$ and $43.4 \%$ when span length increases from 8 to $13.33 \mathrm{~m}$. This indicates that the usage of post tensioning in structures with large spans is very efficient in minimising the material requirements for that particular structure. In the case of the $6.67 \mathrm{~m}$ span, it is apparent that a very large reduction in steel mass is obtainable due to design reasons.

The $6.67 \mathrm{~m}$ span was the only span where tensile stresses were below $0.25 \sqrt{f_{c}^{\prime}}$, resulting in a very economical design for the post tensioned slabs. This was because crack control in the form of unstressed bars at 300mm spacing were not required, resulting in a small mass of steel being required for these slabs. Further, temperature and shrinkage requirements were easily satisfied as no additional reinforcement was suggested to satisfy the relevant design codes.

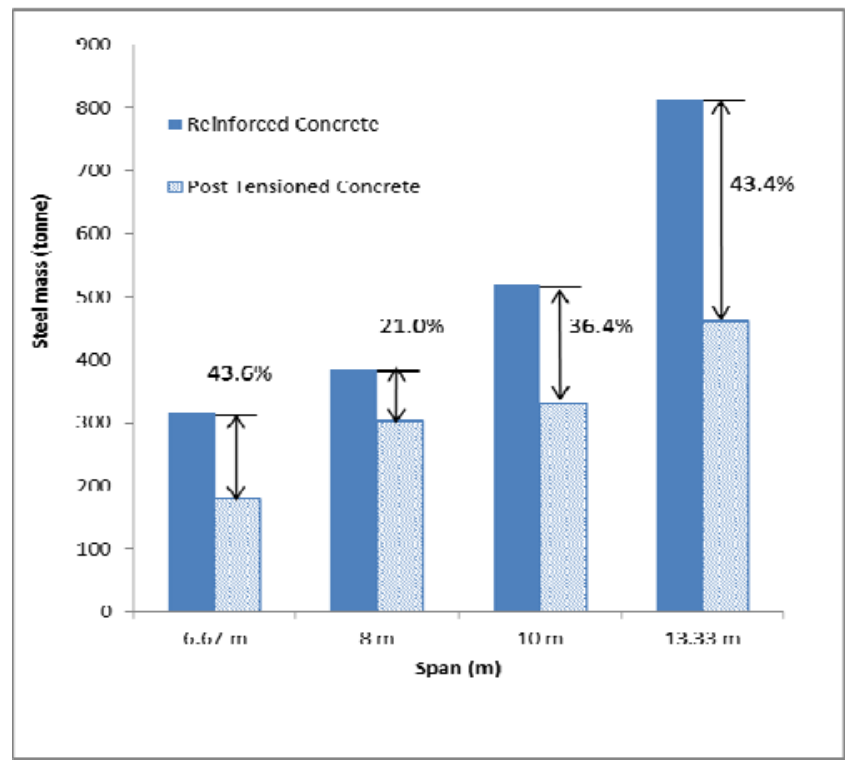

Figure 3 Steel mass of Reinforced and Post Tensioned Concrete buildings

Values for embodied energy and global warming potential were determined for comparison of the environmental performance of the two structures when alternate construction methods were employed.

The calculated embodied energy resulting from the concrete volume and steel mass requirements for the individual floor and roof slabs are displayed in Figures 4 to 7 respectively. Results indicate similar extensive savings are experienced in both the embodied energy of the floor and roof slabs. These results are presented for each of the four spans investigated for both the conventionally reinforced and post tensioned floor and roof slabs.

The environmental impacts of each office structure are displayed in Figures 4 to 8 below. Results indicate large reductions may be achieved in the embodied energy of material requirements in the 
floor and roof slabs. The total environmental impacts in each slab are indicated as individual contributions of the concrete and steel components. Comparison of the unit environmental impacts for steel and concrete by mass, indicate the embodied energy of steel is at least 25 times that of concrete.

Figure 8 displays the environmental impacts resulting from material requirements in the office structure employing post tensioned slab construction as a percentage of impacts resulting from the office structure employing conventional reinforced slab construction methods. Results indicate that 28.8 to $40.9 \%$ saving in the global warming potential may be achieved through the application of more efficient post tensioned concrete building construction methods to achieve comparable structural requirements in a typical ten story office structure for construction in the South East Queensland Regions.

Environmental impacts in both structures can be seen to result mainly from the concrete, which contributes approximately $51 \%$ to $63 \%$ of the embodied energy and $50 \%$ to $62 \%$ of the global warming potential. This variation occurs as a result of the greater contribution from concrete in the overall structure mass (over 97\%). Results indicate environmental efficiencies are achieved through both the material reductions of steel and concrete. Overall, a $28.8 \%$ to $40.9 \%$ reduction in the global warming potential was observed as well as a $23 \%$ to $37 \%$ reduction in construction materials through the utilisation of post tensioned construction methods.

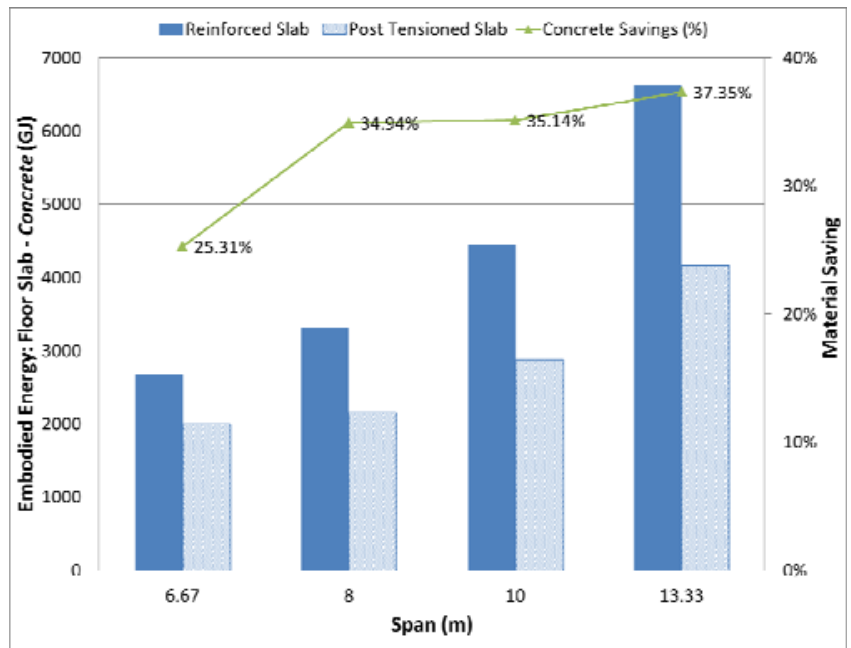

Figure 4 Embodied Energy value of concrete for Floor slab

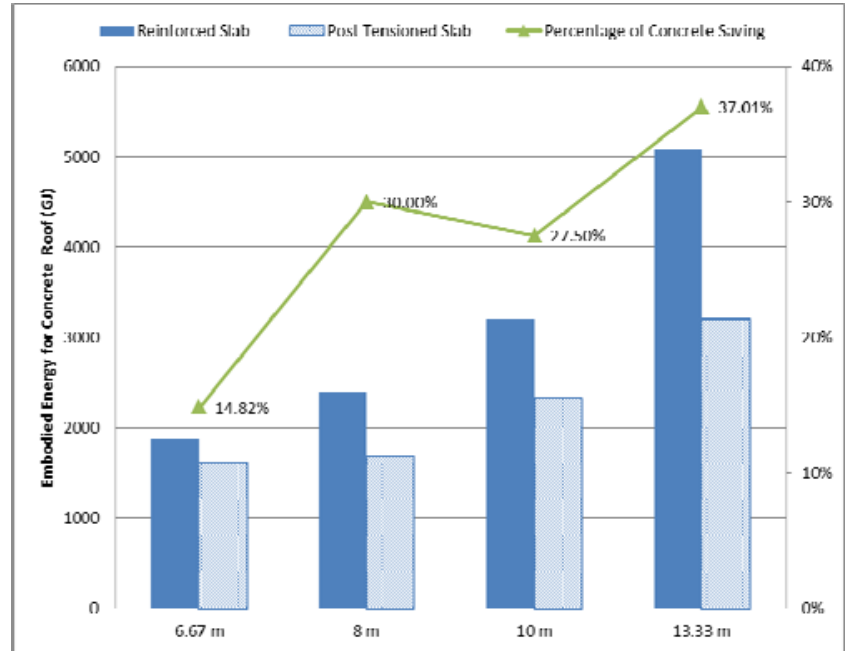

Figure 5 Embodied Energy value of concrete for Roof slab

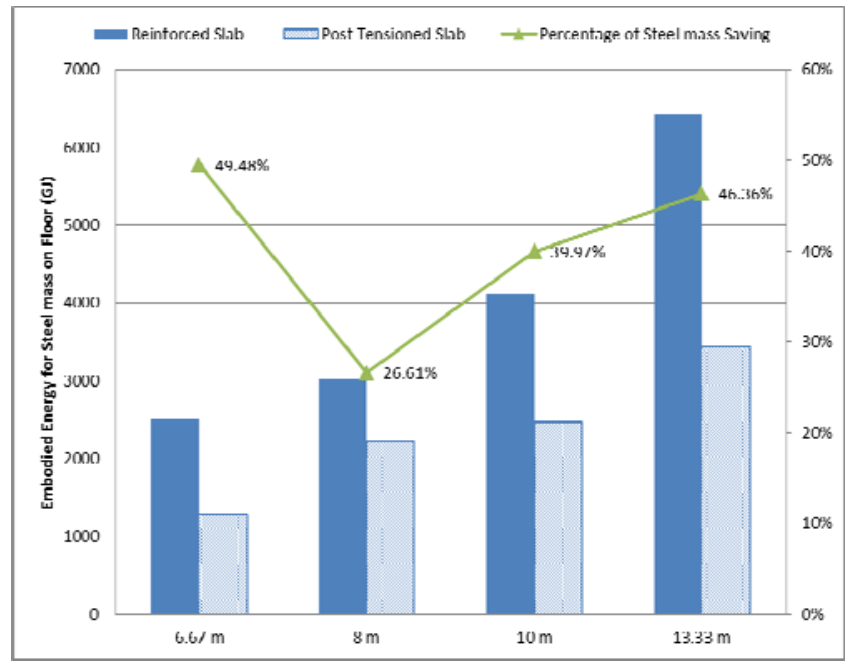

Figure $6 \mathrm{EE}$ value of concrete for roof slab

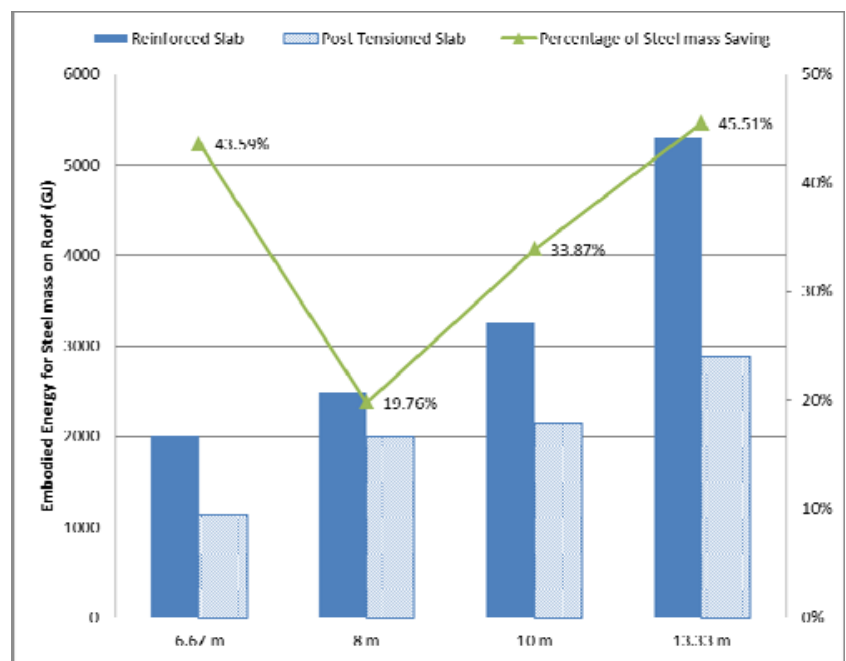

Figure $7 \mathrm{EE}$ value of concrete for roof slab 


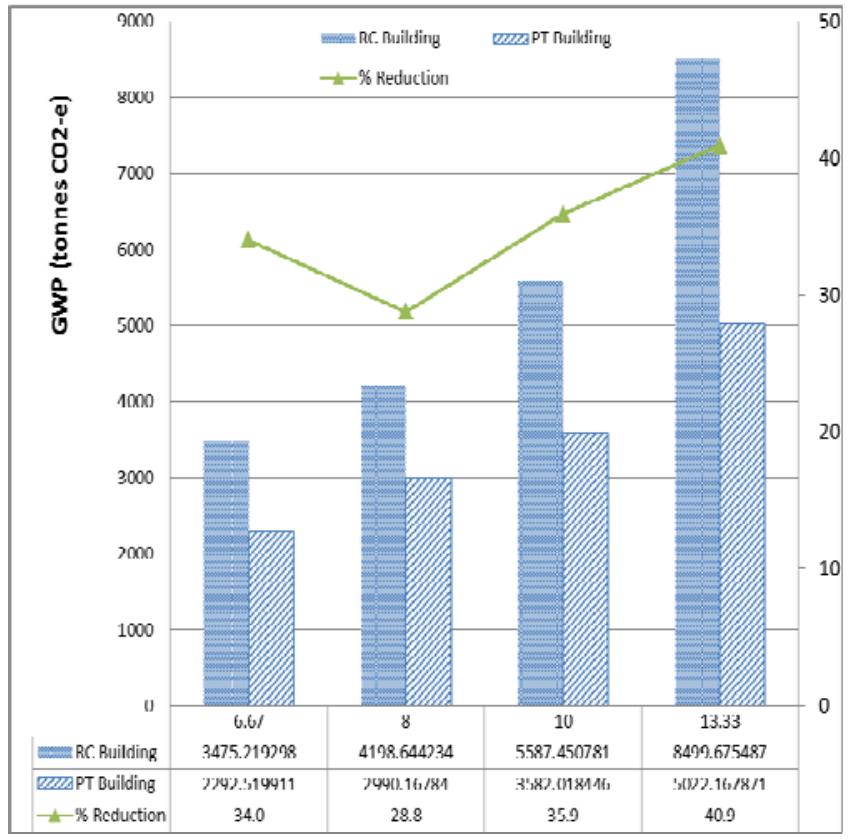

Figure 8 Global Warming Potential of RC and PT buildings

\section{CONCLUSION}

The results obtained from this study can be divided into two key components as determined from the structural analysis and the subsequent environmental impact assessment. The findings are divided into material requirements of the structures and the environmental impacts associated with these structures.

The findings obtained from the structural analysis indicate a significant reduction in material requirements can be achieved through the implementation of post tensioned construction methods for the typical office building investigated. The use of post tensioning is able to significantly reduce the concrete volume and steel mass required for a structure, and further result in significant overall building weight reductions leading to potential foundation material savings. It was found that span length greatly influenced the achievable reductions in material savings when post tensioning is utilised.

Due to the carbon dioxide equivalent emissions being directly proportional to the embodied energy, the savings in embodied energy and global warming potential through the use of post tensioning was found to be almost identical. It was evident that the use of post tensioning in structures of spans smaller than 8 metres is potentially unnecessary from an environmental standpoint as there is very little improved environmental performance as the embodied energy of these structures are equal to or less than the embodied energy of spans $10 \mathrm{~m}$ and larger when post tensioning is utilised.

The outcomes from these results provide confirmation that post tensioned construction can achieve a capital embodied environmental impact cost that is less than that of the fully reinforced option. The ef- fectiveness of post tensioning is also seen to increase with a corresponding increase in span length.

\section{REFERENCES}

Australia Bureau of Statistics (ABS). 2010. Population Projections, Australia Cat. No. 3222.0

Aye, L, Ngo, T, Crawford, RH, Gammampila, R \& Mendis, P.

2011. Life cycle greenhouse gas emissions and energy analysis of prefabricated reusable building modules, Energy and Buildings, (47) 159-168.

Cement and Concrete Association of Australia. 2003. Guide to Long-Span Concrete Floors, TechMedia Publishing Pty Ltd

Crawford, R.H. 2011. Life Cycle Assessment in the Built Environment, Taylor and Francis, London.

Hasegawa, T. 2003. Environmentally sustainable buildings: Challenges and policies, Organisation for Economic Cooperation and Development, OECD, Paris.

Kelly, E. \& McCarthy, T.J. 2008. Sustainable Structural Design: Conceptual Design of Adaptable Commercial Buildings, Australasian Structural Engineering Conference (ASEC), Melbourne, Australia, 26-27 June 2008.

Kestner, D. M. 2007. Sustainable Design, Structure Magazine, September.

Lawson, B. 2000. Embodied energy of building materials, Environment Design Guide, PRO2, Melbourne.

Norgate, T.E. \& Rankin, W.J. 2002. The role of metals in sustainable development, The International Conference on the Sustainable Processing of Minerals, May.

Palich, N., Day, M \& Hes, D. 2011. Glossary of environmentally sustainable design. Environment Design Guide, (70) pp. 1-24

Standards Australia. 2009. Australian Standard 3600 Concrete Structures, SAI Global, Sydney

Treloar, G., Fay, R. Ilozor, B. \& Love, P. 2001. Building materials selection. greenhouse strategies for built facilities, Facilities (19) 139-149

Walker-Morison, A., Grant, T. \& McAlister, S. 2007. The environmental impact of building materials. Environment Design Guide, Melbourne.

World Green Building Council. 2009. How green building is shaping the global shift to a low carbon economy. World Green Building Council, Ontario

Yeo, D. \& Gabbai, R.D. 2011. Sustainable design of reinforced concrete structures through embodied energy optimization, Energy and Buildings, (43) pp. 2028-2033. 